\title{
Factors associated with physical activity of women aged over 75 in South Korea
}

\author{
Soon-Rim Suh ${ }^{1, *}$, Young-Mi Kim² \\ ${ }^{1}$ College of Nursing, Kyungpook National University, Daegu, Korea \\ ${ }^{2}$ Department of Nursing, Hosan University, Gyeongsan, Korea
}

Physical activity (PA) and the activity-related factors of aged women dwelling in a city community of Korea were examined for 253 participants aged over 75, regarding their socio-demographic characteristics, health status, physical performance, depression, cognitive function, self-efficacy, outcome expectations, and PA. Descriptive statistics, analysis of covariance, Pearson correlation, and multiple regressions were performed to analyze cross-sectional data. The data indicated the participants carry out low-intensity physical activities, such as house chores, light gardening, and walking for pleasure. Moderate and vigorous-intensity physical activities were performed rare. The frequency per week was $15.62 \pm 8.60$ for all listed activities. Frequency of PA decreased significantly in participants aged over 80 , of poor perceived health, depression, and cognitive decline. There was a negative correlation between PA and the figure 8 walks $(r=-0.20, P=0.002)$. PA showed significantly positive correlation with self-efficacy $(r=0.34$, $P=0.001)$ and outcome expectations $(r=0.36, P=0.001)$. In a regression analysis, explanation rate of factors influencing $P A$ was $21.9 \%(P=$ 0.001). Outcome expectations $(\beta=0.23)$, cognitive function $(\beta=-0.20)$, and self-efficacy $(\beta=0.19)$ influenced the PA. These findings indicate that interventions stimulating cognitive function and enhancing positive expectation and self-confidence should be included for PA promotion of older women aged 75 years and over.

Keywords: Cognition, Exercise, Frail elderly, Self-efficacy, Women

\section{INTRODUCTION}

As the life expectancy of older adults continues to increase they comprise the fastest growing segment of the population in high-income countries, South Korean women, for an example, are projected to be over 86.7 years in 2030 (Kontis et al., 2017). The rapid rise of older population is projected to increase proportion of chronic disease and life dependency (McPhee et al., 2016). It poses an important public health challenge to maintain the quality of life and to functional independency in their later life due to the extended life span (Katz et al., 1983).

Physical activity (PA) of older adults is a key for the improvement of cardiovascular, musculoskeletal and psycho-social health, cognitive and physical functioning (Taylor et al., 2004). Despite these benefits, PA of the elderly women is generally of a low intensity and tend to confine housework and less vigorous activities than men (Giuli et al., 2012), and it is more obvious with advancing age (Keadle et al., 2016). This suggests that women aged over 75 may be a focused target population when considering PA intervention studies for healthy aging.

Several studies have investigated the socio-demographical, physical and psychological correlates of PA of older women. It was shown that age, income, and education level significantly correlated with PA (Lin et al., 2017), so were the subjective health status (Eifert et al., 2014) and lower-extremity function (Aoyagi et al., 2009). These studies, however, provided insufficient evidences to examine whether these factors predict the PA of women over 75 years. The relationship between depression and PA may be bidirectional (Ku et al., 2012). In a systematic overview of meta-analysis, exercise significantly reduces depressive symptoms (Catalan-Matamoros et al., 2016). Only two studies showed that depression predicts PA in older adults over 65 years (Giuli et al.,
${ }^{\star}$ Corresponding author: Soon-Rim Suh (D) https://orcid.org/0000-0003-4578-9685 College of Nursing, Research Institute of Nursing Science, Kyungpook National University, 680 Gukchaebosang-ro, Jung-gu, Daegu 41944, Korea Tel: +82-53-420-4931, Fax: +82-53-421-2758, E-mail: srsuh@knu.ac.kr Received: April 26, 2018 / Accepted: May 16, 2018
This is an Open Access article distributed under the terms of the Creative Commons Attribution Non-Commercial License (http://creativecommons.org/licenses/by-nc/4.0/) which permits unrestricted non-commercial use, distribution, and reproduction in any medium, provided the original work is properly cited. 
2012; McKee et al., 2015). It is also necessary to investigate whether depression is a significant predictor for women over 75 years. When compared with the PA group of elderly females, cognitive function of the highest PA group was significantly less decreased (Yaffe et al., 2001). A previous study demonstrated that cognitive function was a good predictive of PA (McKee et al., 2015), although other studies have found that cognitive function did not affect PA (Ferreira et al., 2010; Giuli et al., 2012). Another study (Zhu et al., 2017) reported that moderate-intensity PA reduces the risk of cognitive impairment. There seems a bidirectional association between PA and cognitive function but more information is needed whether the cognitive function predicts PA. Elderly women aged 75 and older mostly demonstrate a low intensity PA rather than a moderate intensity PA; thus, further studies are needed to understand the relevance of low-intensity daily PA to cognitive function (Beckett et al., 2015). Self-efficacy has been considered related to PA (Bauman et al., 2012) and outcome expectations are also reported to affect exercise participation and PA in older adults (Resnick, 2001). It was reported that the strongest predictor of health behaviors in elderly women is self-efficacy, followed by outcome expectations (Conn, 1997). Studies of the physical activities of middle-aged and elderly women in Taiwan revealed that self-efficacy has a significant correlation with PA, but not in a regression analysis (Lin et al., 2017). In another study, PA increases significantly when having high self-efficacy, not outcome expectations (Mielenz et al., 2013). These findings indicate a need for further study for the influence of self-efficacy and outcome expectations on PA of older women.

Specifically, only few studies have included a multivariate evaluation of factors related to PA focused on older women in their later stage. Thus, there is a need to investigate the effects of subjective health status, physical performance, depression, cognitive function, self-efficacy, and expectation on the PA of older women in their later life stage in particular.

In this context, aims of this study were to investigate the PA frequency of a sample of community-dwelling older women over 75 in South Korea, and analyze the predictors of PA. Results identifying the current state and predictors of PA can provide basic data for the design of intervention programs to enhance PA in this population.

\section{MATERIALS AND METHODS}

\section{Study setting and participants}

Study participants were recruited from elderly women regis- tered at one senior club and three senior centers in the Daegu city of South Korea. Study inclusion criteria were as follows: (a) women aged over 75, (b) who replied independently on the questions about their activities of daily living (eating, bathing, getting dressed, using the bathroom, moving, walking), (c) who were capable of communication and social activity, (d) who volunteered to participate in this study, and (e) who did not participate in any other structured PA program.

A sample size greater than 252 people was needed for an oneway analysis of variance using a test power of 0.95 , a significance level of 0.05 , and a medium effect size (Faul et al., 2009). Initially, 278 older women were included from the accessible population (1,470 total individuals). However, 25 individuals provided insufficient responses or did not complete the questionnaires. Therefore, the final analysis was conducted for data collected from 253 participants.

This study was approved by the Institutional Review Board of Kyungpook National University (approval number: KNU 201628).

\section{Measurements}

The participants were assessed for the general characteristics including age (75-79, 80-84, or 85 years and over), level of education (illiteracy, elementary school or higher), living arrangement (alone, or not alone), perceived economic level (low, middle, or high), comorbidity (yes, or no), and subjective health status (very good, good, moderate, poor, or very poor).

The figure- 8 walk test (F8WT) is a measure of walking skills in daily life (Hess et al., 2010). Individuals were asked to walk a figure 8 around two cones placed $1.5 \mathrm{~m}$ apart. The participant was instructed to stand at the middle point between the two cones and to begin walking at a usual pace. The pattern consisted of walking on curved paths, clockwise and counterclockwise, with straight-path walking between the curved paths. One trained investigator recorded the time to complete the F8WT. A longer time to complete the task is considered poorer performance.

Depressive symptoms were measured using the Short Geriatric Depression Scale developed by Yesavage and Sheikh (1986). Total scores were obtained by adding one point for each response that was symptomatic of depression, resulting in a score ranging from 0 to 15 , with higher scores indicating greater depressive symptoms. A score $\geq 5$ (cutoff value) suggests depression. Cronbach $\alpha$ was 0.91 for this study.

The Mini Mental State Examination measured cognitive function (Folstein et al., 1975). It is composed of items such as orien- 
tation, registration, attention and calculation, recall and language. We used the total score, which ranged from 0 to 30 points, with higher scores indicating better cognitive function. The score below 24 indicates cognitive impairment. Cronbach $a$ for this study was 0.94 .

Self-Efficacy for Exercise developed by Resnick and Jenkins (2000) is a 9-item questionnaire regarding the ability to continue exercising despite barriers, with scores ranging from 0 (not confident) to 10 (very confident). Items include asking participants how confident they are in exercising when they are having pain or; fatigue or in busy or stressful situations. It is scored by summing the numerical ratings for each response and dividing that value by the number of responses. A higher score represents better self-efficacy. Cronbach $\alpha$ for this study was 0.84 .

The Outcome expectations for exercise 2, which anticipates the consequences of a given behavior, developed from the study of Resnick (2005) focuses on the perceived consequences of exercise for older adults. The questionnaire consists of 13 items measuring nine positive and four negative outcomes expectations. The test uses a 5-point scale, ranging from 1 (not at all) to 5 (absolutely agree). It is scored by summing the numerical ratings for each response and dividing this value by the number of responses. A higher score indicates positive expectations for the outcomes. Cronbach a for this study was 0.89 .

PA was assessed using the questionnaire for the Community Health Activities Model Program for Seniors developed by Stewart et al. (2001). This measurement assesses the frequency of different activities and ranges from light to vigorously intense activities, which was completed in a typical week over the past 4 weeks. Participants reported whether they had engaged in each activity (yes/no), and the frequency per week.

\section{Data collection}

The data collection for this study consisted of one-on-one interviews and measurement by trained research assistants from March 11 to April 28, 2016. A verbal presentation was given by the investigator to the board regarding the research purpose and overall study procedure. All participants voluntarily agreed to participate in the study and signed an informed consent after receiving information about the study goal, data collection, and confidentiality. Participants were told that the data collection process could be terminated at any time without penalty. Investigators were trained on the survey methods and direct measurement methods to ensure consistent measurements prior to the investigation.

\section{Data analysis}

The collected data were analyzed using IBM SPSS Statistics ver. 21.0 (IBM Co., Armonk, NY, USA). Descriptive statistics were used for general characteristics, study variables such as physical performance, depressive symptoms, cognitive function, self-efficacy, outcome expectations, and PA. The analysis of covariance (covariance; age) was used to examine the difference in PA according to general characteristics. Pearson correlation coefficient was used to determine the relationships between measured variables. Multiple regression analyses were performed to determine the predictors of PA among older women. The categorical variable was changed to a dummy variable before the analysis.

\section{RESULTS}

\section{General characteristics of the participants}

The average age of the 253 participants was 79.8 years (age range, $75-94$ years). In addition, $53.7 \%$ of the subjects had education higher than the elementary school, $49.8 \%$ were living alone, and $58.5 \%$ were economically above the average. Furthermore, $83.8 \%$ of the participants had chronic diseases, such as hypertension, diabetes, and arthritis. In all, $67.2 \%$ of the participants had a moderate or better subjective health status. For the F8WT, $57.3 \%$ of the subjects belonged to the average or higher groups, and the mean score of the F8WT was $42.7 \mathrm{sec}$. Regarding the presence or absence of depressive symptoms, $67.6 \%$ of the patients had no depressive symptoms. The mean score of depressive symptoms was 3.4/15. Furthermore, $68.0 \%$ of the participants belonged to the normal group in terms of cognitive function. The mean score for the MMSE was 24.9/30. The mean scores of self-efficacy and outcome expectations were 46.2/90 and 51.7/65, respectively (Table 1).

\section{PA of the participants}

The frequency of PA in participants was 15.6 times per week. Light work in the house (sweeping) was as frequent as 4.6 times per week, followed by walking leisurely for pleasure 3.6 times per week. PA related to recreation/leisure activity and aerobic/exercise activity was found to be very rare with the exception of walking (Table 2).

\section{PA according to the general characteristics of the participants}

The mean score for PA differed significantly depending on the age $(F=6.32, P=0.002)$. The 75 - to 79 -year-old age group 
Table 1. Characteristics of participants $(n=253)$

\begin{tabular}{|c|c|}
\hline Variable & Value \\
\hline Age (yr) & $79.82 \pm 3.99(75-94)$ \\
\hline $75-79$ & $140(55.3)$ \\
\hline $80-84$ & $79(31.2)$ \\
\hline$\geq 85$ & $34(13.4)$ \\
\hline \multicolumn{2}{|l|}{ Education } \\
\hline Illiteracy & $117(46.2)$ \\
\hline z Elementary school & $136(53.8)$ \\
\hline \multicolumn{2}{|l|}{ Living arrangement } \\
\hline Alone & $126(49.8)$ \\
\hline Not alone & $127(50.2)$ \\
\hline \multicolumn{2}{|l|}{ Perceived economic level } \\
\hline Low & $105(41.5)$ \\
\hline Middle or high & $148(58.5)$ \\
\hline \multicolumn{2}{|l|}{ Comorbidity } \\
\hline Yes & $212(83.8)$ \\
\hline No & 41 (16.2) \\
\hline \multicolumn{2}{|l|}{ Subjective health status } \\
\hline Poor or very poor & 83 (32.8) \\
\hline Moderate, good or very good & $170(67.2)$ \\
\hline Depression & $3.60 \pm 3.99(0-15)$ \\
\hline Normal (0-4) & $171(67.6)$ \\
\hline Depression $(\geq 5)$ & $82(32.4)$ \\
\hline Cognitive function & $24.85 \pm 3.39(16-30)$ \\
\hline Normal ( $\geq 24)$ & $172(68.0)$ \\
\hline Decline $(<24)$ & 81 (32.0) \\
\hline Figure 8 walks & $42.70 \pm 12.69(20-84)$ \\
\hline Self-efficacy & $46.16 \pm 26.16(0-90)$ \\
\hline Outcome expectations & $51.71 \pm 8.91(28-65)$ \\
\hline
\end{tabular}

Values are presented as mean \pm standard deviation (range) or number (\%).

showed higher scores of PA compared with the other age groups. When the results of the analysis of PA by general characteristics were adjusted for age (covariate), individuals with a moderate or better level of subjective health status showed a higher frequency of PA compared to the other groups $(F=5.45, P=0.020)$. Compared to the depressed group, the nondepressed group showed a significantly higher PA $(F=4.30, P=0.039)$. The group with normal cognitive function had significantly higher PA compared to the cognitive dysfunction group $(F=8.93, P=0.003)$ (Table 3). There was a negative correlation between PA and F8WT $(r=$ -0.20, $P=0.002$ ). A positive relationship was found between self-efficacy and PA $(r=0.34, P<0.001)$, and between outcome expectations and PA $(r=0.36, P<0.001)$ (Table 4$)$.

\section{Predictors of PA}

To identify the factors that affect the PA of elderly women,
Table 2. Physical activity of participants $(n=253)$

\begin{tabular}{|c|c|c|c|c|}
\hline \multirow{2}{*}{ Items } & \multirow{2}{*}{ MET } & \multirow{2}{*}{ Frequency } & \multicolumn{2}{|c|}{ Physical activity } \\
\hline & & & No & Yes \\
\hline Stretching/flexibility exercises & 2.0 & $0.81 \pm 2.01$ & $208(82.2)$ & $45(17.8)$ \\
\hline Yoga or Tai chi & 2.0 & $0.28 \pm 0.91$ & $224(88.5)$ & $29(11.5)$ \\
\hline Light gardening (watering plants) & 2.5 & $1.38 \pm 2.25$ & $149(58.9)$ & $104(41.1)$ \\
\hline Calisthenics & 2.5 & $0.17 \pm 0.84$ & $239(94.5)$ & $14(5.5)$ \\
\hline $\begin{array}{l}\text { Light work around the house } \\
\text { (sweeping) }\end{array}$ & 2.5 & $4.63 \pm 2.50$ & $23(9.1)$ & $230(90.9)$ \\
\hline Walk leisurely for pleasure & 2.5 & $3.63 \pm 3.01$ & $85(33.6)$ & $168(66.4)$ \\
\hline Walk to do errands & 2.5 & $1.35 \pm 2.36$ & $169(66.8)$ & $84(33.2)$ \\
\hline Light strength training ${ }^{*}$ & 3.0 & $0.06 \pm 0.45$ & $248(98.0)$ & $5(2.0)$ \\
\hline Play golf walking* & 3.0 & $0.02 \pm 0.25$ & 252 (99.6) & $1(0.4)$ \\
\hline Swim gently* & 3.0 & $0.04 \pm 0.26$ & $250(98.8)$ & $3(1.2)$ \\
\hline Aerobics or aerobic dancing* & 3.5 & $0.13 \pm 0.87$ & $246(97.2)$ & $7(2.8)$ \\
\hline $\begin{array}{l}\text { Heavy work around the house } \\
\text { (washing windows) }\end{array}$ & 3.5 & $0.94 \pm 1.63$ & $153(60.5)$ & $100(39.5)$ \\
\hline Walk fast or briskly for exercise* & 3.5 & $1.09 \pm 2.23$ & $195(77.1)$ & $58(22.9)$ \\
\hline Heavy gardening (raking) ${ }^{*}$ & 4.0 & $0.16 \pm 0.77$ & $235(92.9)$ & $18(7.1)$ \\
\hline Ride a bicycle* & 4.0 & $0.19 \pm 1.03$ & $244(96.4)$ & $9(3.6)$ \\
\hline Dance ${ }^{*}$ & 4.5 & $0.02 \pm 0.20$ & $249(98.5)$ & $4(1.5)$ \\
\hline Aerobic machines* & 5.0 & $0.05 \pm 0.51$ & 250 (98.8) & $3(1.2)$ \\
\hline $\begin{array}{l}\text { Play basketball, soccer, } \\
\text { or racquetball }\end{array}$ & 5.0 & $0.06 \pm 0.59$ & $250(98.8)$ & $3(1.2)$ \\
\hline Swim moderately, fast* & 5.0 & $0.01 \pm 0.13$ & 252 (99.6) & $1(0.4)$ \\
\hline Walk or Hike uphill* & 6.0 & $0.19 \pm 0.94$ & $238(94.1)$ & $15(5.9)$ \\
\hline Jog/run* & 7.0 & $0.38 \pm 1.50$ & $235(92.9)$ & $18(7.1)$ \\
\hline Total & - & $15.62 \pm 8.60$ & - & - \\
\hline
\end{tabular}

Values are presented as mean \pm standard deviation or number (\%). MET, metabolic equivalent of task.

*Moderate physical activity.

multiple regression analysis was performed using age, subjective health status, F8WT, depression, cognitive function, self-efficacy and outcome expectations. The model was significant, explaining $21.9 \%$ of the variance in $\mathrm{PA}(F=9.80, P=0.001)$. Among these, outcome expectations ( $\beta=0.23, P=0.002)$ was the strongest predictor, followed by cognitive function $(\beta=-0.20, P=0.002)$, and self-efficacy $(\beta=0.19, P=0.007)$ (Table 5).

\section{DISCUSSION}

The aim of this study was to identify PA and it's predictors among community-dwelling older women aged over 75 years. The frequency of all PA was 15.6 time per week. This finding is slightly higher than the 13.3 times per week for the American women as reported in the study by Stewart et al. (2001). The participants in this study were found to perform mostly low-intensity 
Table 3. Physical activity according to the general characteristics of the participants ( $n=253$ )

\begin{tabular}{|c|c|c|}
\hline Variable & Frequency & $F(P)$ \\
\hline \multicolumn{3}{|l|}{ Age } \\
\hline $75-79^{a}$ & $17.16 \pm 8.91$ & $6.32(0.002)$ \\
\hline $80-84^{b}$ & $14.35 \pm 8.15$ & $a>b, c$ \\
\hline$\geq 85^{c}$ & $12.03 \pm 6.74$ & \\
\hline \multicolumn{3}{|l|}{ Education } \\
\hline Illiteracy & $14.93 \pm 8.14$ & $0.41(0.521)$ \\
\hline z Elementary school & $16.16 \pm 8.95$ & \\
\hline \multicolumn{3}{|l|}{ Living arrangement } \\
\hline Alone & $15.65 \pm 9.30$ & $0.25(0.620)$ \\
\hline Not alone & $15.53 \pm 7.87$ & \\
\hline \multicolumn{3}{|l|}{ Perceived economic level } \\
\hline Low & $15.55 \pm 8.51$ & $0.03(0.868)$ \\
\hline Middle or high & $15.62 \pm 8.68$ & \\
\hline \multicolumn{3}{|l|}{ Comorbidity } \\
\hline Yes & $16.00 \pm 7.84$ & $0.06(0.802)$ \\
\hline No & $15.51 \pm 8.74$ & \\
\hline \multicolumn{3}{|l|}{ Subjective health status } \\
\hline Poor or very poor & $13.76 \pm 7.58$ & $5.45(0.020)$ \\
\hline Moderate, good or very good & $16.49 \pm 8.93$ & \\
\hline \multicolumn{3}{|l|}{ Depression } \\
\hline Normal (0-4) & $16.49 \pm 8.99$ & 4.30 (0.039) \\
\hline Depression $(\geq 5)$ & $13.73 \pm 7.41$ & \\
\hline \multicolumn{3}{|l|}{ Cognitive function } \\
\hline Normal ( $\geq 24)$ & $16.97 \pm 8.91$ & $8.93(0.003)$ \\
\hline Decline $(<24)$ & $12.67 \pm 7.07$ & \\
\hline
\end{tabular}

Values are presented as mean \pm standard deviation.

activity (2-2.5 metabolic equivalent of tasks [METs]), such as household chores and light walking, whereas moderate-intensity activity (3 METs) was not performed or performed less than once per week. The participants do not engage in PA appropriate for maintaining and promoting health. World Health Organization (2010) recommended at least 150 min per week of moderate-intensity PA for health benefits in older adults. It is consistent with the data obtained in previous studies, in which older women performed daily domestic activities such as walking and housework (Plonczynski et al., 2008). It suggests the possibility of developing functional dependence among women over 75 years old in the future and of becoming vulnerable elderly, which reduces the quality of life related to health. Therefore, it is important to develop a strategy that could involve women over 75 in moderate intensity PA.

Women of 85 years and over performed lower PA than those of 75-84 years in this study, which is consistent with another study (Eifert et al., 2014). But age was not a significant predictor of PA
Table 4. Correlation between physical activity and figure 8 walks, self-efficacy, and outcome expectations $(n=253)$

\begin{tabular}{lcccc}
\hline \multirow{2}{*}{ Variable } & \multicolumn{4}{c}{$r(P$-value $)$} \\
\cline { 2 - 5 } & $\begin{array}{c}\text { Physical } \\
\text { activity }\end{array}$ & $\begin{array}{c}\text { Figure } 8 \\
\text { walks }\end{array}$ & Self-efficacy & $\begin{array}{c}\text { Outcome } \\
\text { expectations }\end{array}$ \\
\hline Physical activity & 1 & & & \\
Figure 8 walks & $-0.20(0.002)$ & 1 & & \\
Self-efficacy & $0.34(0.001)$ & $-0.19(0.003)$ & 1 & 1 \\
Outcome expectations & $0.36(0.001)$ & $-0.24(0.001)$ & $0.60(0.001)$ & 1 \\
\hline
\end{tabular}

Table 5. Multiple regression analysis of study variables

\begin{tabular}{lcccc}
\hline \multirow{2}{*}{ Variable } & \multicolumn{4}{c}{ Physical activity (F/w) } \\
\cline { 2 - 5 } & $\mathrm{B}$ & $\mathrm{SE}$ & $\beta$ & $P$ \\
\hline Age & -0.24 & 0.13 & -0.11 & 0.068 \\
Subjective health status $^{\mathrm{a})}$ & 0.23 & 1.16 & 0.01 & 0.842 \\
Depression $^{\text {b) }}$ & 0.48 & 1.17 & 0.03 & 0.685 \\
Cognitive function $^{\mathrm{c})}$ & -3.58 & 1.12 & -0.20 & 0.002 \\
Figure 8 $^{\text {walks }}$ & -0.10 & 0.04 & -0.02 & 0.824 \\
Self-efficacy $^{\text {Outcome expectations }}$ & 0.06 & 0.02 & 0.19 & 0.007 \\
& 0.22 & 0.07 & 0.23 & 0.002 \\
& $R^{2}=0.219, F=9.796, P=0.001$, Durbin-Watson $=1.373$ \\
\hline
\end{tabular}

$\mathrm{SE}$, standard error; F/w, frequency per week.

${ }^{a}$ Poor or very poor group is a reference value. ${ }^{b}$ Depression group is a reference val-

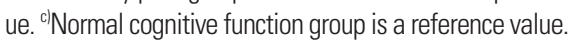

in the the regression model. Participants with good subjective health status had significantly higher PA than those with poor subjective health status, which was consistent with previous studies (Browning et al., 2009; Eifert et al., 2014; Giuli et al., 2012). Nevertheless, subjective health status was not a significant predictor of PA among older women in the regression model. This result was different from another study that subjective health status predicted PA in Italian elderly (Giuli et al., 2012). Because of insufficient information on PA of older and oldest old women, there is a need to study further for determining whether subjective health status leads to perform more PA in older women. Although non-depressed participants performed PA more than the depressed, depressive symptoms were not a significant predictor of PA in the current study. The results were inconsistent with previous studies (Giuli et al., 2012; McKee et al., 2015) that depressive symptoms predicted PA significantly. Depressive symptoms affect the level of physical functioning and physical functioning leads to more PA (Giuli et al., 2012). On this basis, it is considered that depressive symptoms do not affect PA directly because most participants in this study showed no problems of physical functioning.

In this study, PA was lower in the cognitive decline group than in the normal group and cognitive function was a significant pre- 
dictor of PA. Cognitive function is an important factor to perform more PA because it is associated with independent daily activities such as judgment and executive function (de Guzman et al., 2015). The finding is consistent with the notion that preexisting cognitive impairment cause a reduction PA (Weuve et al., 2004) and cognitive function of older adults affects PA significantly (de Guzman et al., 2015; McKee et al., 2015). It shows that intervention for maintain and promoting cognitive function could activate PA.

Walking is a complex exercise technique based on a variety of balance-control abilities, and a brain-body interaction allows walking and rapid adaptation to change depending on the circumstances (Capaday, 2002). The F8WT is a valid tool to assess walking performance and balance in older adults (Hess et al., 2010). In this study, there was a negative weak correlation between the F8WT and PA, but F8WT was not a significant predictive factor of PA. Self-efficacy is a person's confidence in one's ability to perform a certain behavior successfully (McAuley et al., 2011). A significant positive relationship was found between PA and self-efficacy and self-efficacy predicted PA in this study. People who have higher self-efficacy tend to hold more positive attitude toward exercise and to engage in more PA (Ayotte et al., 2010). This finding was similar to the results obtained by Morris et al. (2008), which also showed a positive correlation between self-efficacy and PA. Therefore, it is necessary to apply a program emphasizing self-efficacy to promote PA. Outcome expectations are the beliefs that performing a specific behavior will lead to a desired outcome. Stronger positive outcome expectations were associated with a greater frequency of PA in the current study. This result is consistent with those obtained from PA studies of older adults (Resnick, 2001; Williams et al., 2005). This finding suggests that participants-more confident in overcoming obstacles and more knowledgeable about the benefits of PA,-perform PA more frequently. Consequently, positive outcome expectations can be considered a target of intervention which would increase PA in older women.

Several limitations should be considered when interpreting the findings of this study. First, the study participants were community-dwelling older adults who were mostly independent in daily living. Therefore, the results cannot be generalized to more disabled women. Second, PA assessment was based on a self-reported questionnaire, which may be subject to a recall bias; although, using subjective measurements among older adults can be valid (Colbert et al., 2011). Despite of these limitations, this study provides cognitive function, self-efficacy and outcome expectations as useful factors in the development of effective interventions to in- crease PA in older women. Therefore, there is a need for a systematic PA program that can increase the current low-intensity activity to moderate-intensity activity to provide health effects in elderly women. As a strategy to promote PA, a PA program needs to include education about the positive incentives for facilitating $\mathrm{PA}$ and strengthen cognitive stimulation and self-confidence motivating PA.

\section{CONFLICT OF INTEREST}

No potential conflict of interest relevant to this article was reported.

\section{ACKNOWLEDGMENTS}

This research was supported by grant from the National Research Foundation of Korea (NRF) funded by the Korean government (NRF-2015R1C1A2A01052834).

\section{REFERENCES}

Aoyagi Y, Park H, Watanabe E, Park S, Shephard RJ. Habitual physical activity and physical fitness in older Japanese adults: the Nakanojo Study. Gerontology 2009;55:523-531.

Ayotte BJ, Margrett JA, Hicks-Patrick J. Physical activity in middle-aged and young-old adults: the roles of self-efficacy, barriers, outcome expectancies, self-regulatory behaviors and social support. J Health Psychol 2010;15:173-185.

Bauman AE, Reis RS, Sallis JF, Wells JC, Loos RJ, Martin BW; Lancet Physical Activity Series Working Group. Correlates of physical activity: why are some people physically active and others not? Lancet 2012;380:258271.

Beckett MW, Ardern CI, Rotondi MA. A meta-analysis of prospective studies on the role of physical activity and the prevention of Alzheimer's disease in older adults. BMC Geriatr 2015;15:9.

Browning C, Sims J, Kendig H, Teshuva K. Predictors of physical activity behavior in older community-dwelling adults. J Allied Health 2009;38: 8-17.

Capaday C. The special nature of human walking and its neural control. Trends Neurosci 2002;25:370-376.

Catalan-Matamoros D, Gomez-Conesa A, Stubbs B, Vancampfort D. Exercise improves depressive symptoms in older adults: an umbrella review of systematic reviews and meta-analyses. Psychiatry Res 2016; 244:202-209.

Colbert LH, Matthews CE, Havighurst TC, Kim K, Schoeller DA. Com- 
parative validity of physical activity measures in older adults. Med Sci Sports Exerc 2011;43:867-876.

Conn VS. Older women: social cognitive theory correlates of health behavior. Women Health 1997;26:71-85.

de Guzman AB, Lacmpuenga PE, Lagunsad AP. Examining the structural relationship of physical activity, cognition, fear of falling, and mobility limitation of Filipino in nursing homes. Educ Gerontol 2015;41: 527-542.

Eifert EK, Wideman L, Oberlin DJ, Labban J. The relationship between physical activity and perceived health status in older women: findings from the Woman's College Alumni Study. J Women Aging 2014;26: 305-318.

Faul F, Erdfelder E, Buchner A, Lang AG. Statistical power analyses using $G^{*}$ Power 3.1: tests for correlation and regression analyses. Behav Res Methods 2009;41:1149-1160.

Ferreira MT, Matsudo SM, Ribeiro MC, Ramos LR. Health-related factors correlate with behavior trends in physical activity level in old age: longitudinal results from a population in São Paulo, Brazil. BMC Public Health 2010;10:690.

Folstein MF, Folstein SE, McHugh PR. "Mini-mental state". A practical method for grading the cognitive state of patients for the clinician. J Psychiatr Res 1975;12:189-198.

Giuli C, Papa R, Mocchegiani E, Marcellini F. Predictors of participation in physical activity for community-dwelling elderly Italians. Arch Gerontol Geriatr 2012;54:50-54.

Hess RJ, Brach JS, Piva SR, VanSwearingen JM. Walking skill can be assessed in older adults: validity of the Figure-of- 8 Walk Test. Phys Ther 2010;90:89-99.

Katz S, Branch LG, Branson MH, Papsidero JA, Beck JC, Greer DS. Active life expectancy. N Engl J Med 1983;309:1218-1224.

Keadle SK, McKinnon R, Graubard BI, Troiano RP. Prevalence and trends in physical activity among older adults in the United States: a comparison across three national surveys. Prev Med 2016;89:37-43.

Kontis V, Bennett JE, Mathers CD, Li G, Foreman K, Ezzati M. Future life expectancy in 35 industrialised countries: projections with a Bayesian model ensemble. Lancet 2017;389:1323-1335.

Ku PW, Fox KR, Chen LJ, Chou P. Physical activity and depressive symptoms in older adults: 11-year follow-up. Am J Prev Med 2012;42:355362.

Lin $\mathrm{CH}$, Chiang SL, Yates P, Tzeng WC, Lee MS, Chiang LC. Influence of socioeconomic status and perceived barriers on physical activity among taiwanese middle-aged and older women. J Cardiovasc Nurs 2017;32:321-330

McAuley E, Szabo A, Gothe N, Olson EA. Self-efficacy: implications for physical activity, function, and functional limitations in older adults.
Am J Lifestyle Med 2011;5:361-369.

McKee G, Kearney PM, Kenny RA. The factors associated with self-reported physical activity in older adults living in the community. Age Ageing 2015;44:586-592.

McPhee JS, French DP, Jackson D, Nazroo J, Pendleton N, Degens H. Physical activity in older age: perspectives for healthy ageing and frailty. Biogerontology 2016;17:567-580.

Mielenz TJ, Kubiak-Rizzone KL, Alvarez KJ, Hlavacek PR, Freburger JK, Giuliani C, Mercer VS, Callahan LF. Association of self-efficacy and outcome expectations with physical activity in adults with arthritis. Arthritis 2013;2013:621396.

Morris KS, McAuley E, Motl RW. Self-efficacy and environmental correlates of physical activity among older women and women with multiple sclerosis. Health Educ Res 2008;23:744-752.

Plonczynski DJ, Wilbur J, Larson JL, Thiede K. Lifestyle physical activity of older rural women. Res Nurs Health 2008;31:501-513.

Resnick B. Reliability and validity of the Outcome Expectations for Exercise Scale-2. J Aging Phys Act 2005;13:382-394.

Resnick B. Testing a model of exercise behavior in older adults. Res Nurs Health 2001;24:83-92.

Resnick B, Jenkins LS. Testing the reliability and validity of the Self-Efficacy for Exercise scale. Nurs Res 2000;49:154-159.

Stewart AL, Mills KM, King AC, Haskell WL, Gillis D, Ritter PL. CHAMPS physical activity questionnaire for older adults: outcomes for interventions. Med Sci Sports Exerc 2001;33:1126-1141.

Taylor AH, Cable NT, Faulkner G, Hillsdon M, Narici M, Van Der Bij AK. Physical activity and older adults: a review of health benefits and the effectiveness of interventions. J Sports Sci 2004;22:703-725.

Weuve J, Kang JH, Manson JE, Breteler MM, Ware JH, Grodstein F. Physical activity, including walking, and cognitive function in older women. JAMA 2004;292:1454-1461.

Williams DM, Anderson ES, Winett RA. A review of the outcome expectancy construct in physical activity research. Ann Behav Med 2005;29: 70-79.

World Health Organization. Global recommendations on physical activity for health. Geneva (Switzerland): World Health Organization; 2010.

Yaffe K, Barnes D, Nevitt M, Lui LY, Covinsky K. A prospective study of physical activity and cognitive decline in elderly women: women who walk. Arch Intern Med 2001;161:1703-1708.

Yesavage JA, Sheikh JI. 9/Geriatric depression scale (GDS) recent evidence and development of a shorter version. Clin Gerontol 1986;5:165-173.

Zhu W, Wadley VG, Howard VJ, Hutto B, Blair SN, Hooker SP. Objectively measured physical activity and cognitive function in older adults. Med Sci Sports Exerc 2017;49:47-53. 